\title{
Controle social e políticas públicas: a experiência dos Conselhos Gestores
}

\author{
Claudio Gurgel
}

Universidade Federal Fluminense

Agatha Justen

Escola Brasileira de Administração Pública e de Empresas (Ebape-FGV)

\begin{abstract}
Este trabalho analisa o exercício do controle social no Brasil, a partir do debate geral que o estimulou e do contexto interno que culminou na criação de espaços institucionalizados para sua aplicação. Tem-se como objetivo avaliar o exercício do controle social, através dos Conselhos Gestores. Por meio de estudos realizados por outros pesquisadores, em Conselhos Gestores de Políticas Públicas, nos três níveis governamentais, e de estudo empírico, constatou-se que a forma como tem acontecido o exercício do controle social, nesses fóruns, distancia-se daquilo que se prevê em lei. Com este quadro de análise, procuramos contribuir para o melhor entendimento dos fatos e para o avanço do próprio controle social, entendido como um patamar elevado e necessário de democratização da gestão pública brasileira.
\end{abstract}

Palavras-chave: democracia; controle social; Conselhos Gestores.

Control social de políticas públicas: la experiencia de los consejos de gestión

Este artículo examina el ejercicio del control social en Brasil, desde el debate general que lo solicite, así como el contexto interno que condujo a la creación de espacios institucionalizados para su aplicación. El objectivo es evaluar el ejercicio del control social a través de los Consejos de Politicas Públicas. Con estudios realizados por otros investigadores en los Consejos de Políticas Públicas de gestión, en los tres niveles de gobierno, y el estudio empírico, se encontró que la forma en que ha ocurrido con el ejercicio del control social en estos foros mucho se aleja de lo que se espera por la ley. A partir de esta mesa, nos referiremos a contribuciones a la comprensión de este hecho y para el avance del control social en sí mismo, entendido como una condición necesaria y un alto nivel de democratización de la gestión pública en Brasil.

Palabras clave: democrácia; control social; Consejos de Gestión.

Artigo recebido em 20 maio 2012 e aceito em 9 nov. 2012. 
Social control and public policies: the experience of the management councils

This paper examines the exercise of social control in Brazil, from the general debate that prompted him, as well as the internal context that led to the creation of institutionalized spaces for your application. The objective is to evaluate the exercise of social control through the Public Policy Management Councils. Through studies conducted by other researchers in Public Policy Management Councils, in the three levels of government, and empirical study, we found that the way it has happened to the exercise of social control in these forums, much moves away from what is expected by law. From this table, we bring contributions to the understanding of this fact and to the advancement of social control itself, understood as a necessary and a high level of democratization of public management in Brazil.

KEY words: democracy; social control; Management Councils.

\section{Introdução}

Há dois séculos, Stuart Mill, ainda que tratando com simpatia o governo representativo, já apontava para insuficiências da democracia representativa e reivindicava a presença do indivíduo desempenhando atividades públicas, ao lado e dentro do aparelho público. Falando do governo, diz Mill (2003:220) que "a forma ideal é aquela em que todo cidadão não apenas tem uma voz no exercício daquele poder supremo, mas também é chamado, pelo menos ocasionalmente, a tomar parte ativa no governo".

Vários outros pensadores sucederam Mill na crítica à democracia representativa, entre eles Schumpeter (1961), Offe (1984), Hirst (1992), Habermas (2002), para não falar dos autores marxistas clássicos.

As críticas aos limites da democracia representativa, usando a expressão de Hirst (1992), estão associadas à desconfiança nas autoridades governamentais, consideradas a influência do grande capital, a burocratização e tecnicização do processo decisório, as negociações e pressões dos grupos de interesse e lobbies com e sobre aquelas autoridades e outros aspectos que tornam duvidosa a formulação das políticas públicas e seus desdobramentos. Tudo isso concorre para um corrosivo descrédito do aparelho público, que fez emergir com expressividade a ideia da participação popular e do controle social, na acepção de controle do aparelho público pela sociedade civil, através de variados meios. ${ }^{1}$

O conceito de cidadão, a partir da caracterização de Marshall (1950), também contribuiu para a suposição de que há uma ação imediata a ser desenvolvida, pelo exercício dos direitos políticos, que reconstitui alguns traços da democracia direta perdida para a democracia representativa.

Nesse sentido, dizer que temos uma "Constituição cidadã" significa dizer que temos uma lei maior estimulante dessa ação imediata do cidadão, ainda que os Conselhos criados

\footnotetext{
${ }^{1} \mathrm{O}$ termo controle social é utilizado por estudiosos de segurança pública, com o sentido de o Estado controlando a sociedade. O conceito utilizado neste trabalho refere-se à sociedade controlando o Estado, acepção que ganhou força contemporaneamente nas ciências sociais e aplicadas.
} 
pela Constituição de 1988 sejam formas indiretas de participação da sociedade civil (Brasil, 2004). A ideia de presença do cidadão nos conselhos da criança e do adolescente, da saúde, da educação, da assistência social e em outros fóruns de políticas públicas empresta um caráter diferenciado ao processo decisório público que se assemelha à democracia direta e assume-se como controle social.

Há, portanto, na Constituição Federal do Brasil, incentivo, ainda que pontual e difuso, a que a sociedade civil se organize e possa influenciar as decisões públicas:

Art. 198. As ações e serviços públicos de saúde integram uma rede regionalizada e hierarquizada e constituem um sistema único, organizado de acordo com as seguintes diretrizes: (...)

III. participação da comunidade.

Art. 204. As ações governamentais na área da assistência social serão realizadas com recursos do orçamento da seguridade social, previstos no art. 195, além de outras fontes, e organizadas com base nas seguintes diretrizes: (...)

II. participação da população, por meio de organizações representativas, na formulação das políticas e no controle das ações em todos os níveis. (Brasil, 2004:138-143)

Os conselhos gestores de políticas públicas, em caráter deliberativo ou consultivo, foram inspirados na Constituição, embora tenham sido criados não por leis específicas no início dos anos 1990.

Por ocasião da implementação da reforma do Estado brasileiro, especialmente no período de 1995 a 1998, o então ministro Bresser-Pereira (1997:37) escreveria, comentando as formas de controle disponíveis, que "o princípio geral é o de que será preferível o mecanismo de controle que for mais geral, mais difuso e mais automático". Concluiria que o mercado cumpre melhor esse papel, porque "através da concorrência obtém-se, em princípio, os melhores resultados com os menores custos" (Bresser-Pereira, 1997:37). Entretanto, dirá também o ministro "que a democracia direta ou controle social é, em seguida, o mecanismo de controle mais democrático e difuso" (Bresser-Pereira, 1997:37). Por isso mesmo, dirá ainda que "através do controle social a sociedade se organiza formal e informalmente para controlar não apenas os comportamentos individuais, mas - e é isto que importa neste contexto — para controlar as organizações públicas" (Bresser-Pereira, 1997:37).

Autores contemporâneos mundialmente influentes, como Habermas, também sugerem que a sociedade civil inverta a relação do contrato hobbesiano e tome seu destino nas mãos.

É portanto importante repercutir este tema, analisá-lo e debatê-lo, no sentido de ajudar a construir a soberania republicana. Em especial, fazer isto no Brasil, onde a experiência dos Conselhos Gestores e a afirmação da cidadania são mais que programas partidários ou políticas de governo, são vontades de Estado, gravadas na Constituição Federal.

O objetivo deste trabalho, por conseguinte, é avaliar o exercício do controle social, como ampliação da democracia na gestão pública, tomando como referência a prática dos Conselhos Gestores. 


\section{Pacto corporativo, cidadania em recesso e Constituição Cidadã}

O Estado brasileiro do século XX passou por diversas transformações que mudaram significativamente seu sentido perante a sociedade. Se o início do século é marcado por um Estado liberal, patrimonialista, excludente, quase completamente descompromissado com as demandas sociais, a partir dos anos 1930 - como solução para um quadro de conflitos e mobilizações sociais crescentes (Santos, 1979) - o Estado brasileiro torna-se fortemente interventor e provedor. Por meio de aliança conservadora, mas politizando as questões sociais e trabalhistas, assume e promove o desenvolvimento econômico e social. ${ }^{2}$ Isso, que ficou conhecido como "pacto corporativo" e criou uma ideologia de consenso, deixou marcas profundas. Fleury (2006:81), a respeito desse período, explica que

as elites econômicas sempre mantiveram, paralelamente à estrutura corporativa, outras modalidades de organização não controladas pelo Estado, que passaram a ter assento privilegiado no planejamento da política industrial. Já a política em relação à classe trabalhadora combinou repressão, exclusão e incorporação controlada da participação e das demandas sociais.

O regime instalado em 1964 fecha o Estado à influência dos trabalhadores na deliberação de políticas sociais, apesar de prosseguir com a caminhada desenvolvimentista (Fleury, 2006:81). Mas, em termos de investimento na área social, os governos militares aprovaram elevados orçamentos. Segundo Santos (1979), essa massa de investimento não foi capaz de diminuir os problemas que se propunha a resolver. Isso porque a política social brasileira desenvolveu-se em contexto de "cidadania em recesso", no qual não há a participação dos beneficiários, não há controle público e os programas são administrados de modo burocrático, no sentido de sem diálogo (ou audiência) com os interessados (Santos, 1979).

A partir dos anos 1970 combinam-se, de um lado, o esgotamento do chamado "milagre brasileiro", e, de outro, o aumento de complexidade da estrutura social. Surgem novos atores (movimentos sociais e organizações não governamentais) trazendo outras demandas, estimulados pela nova dinâmica mundial globalizada, e tornando insustentável o sistema de representação vigente até então.

A Constituição de 1988, conhecida como a "Constituição Cidadã", foi a expressão das demandas por democracia, cidadania e justiça reprimidas em grande parte do século XX, determinando assim formas mais amplas e democráticas de condução das políticas públicas.

A despeito da tradição latino-americana baseada na civil law, a instituição de mecanismos democráticos na Constituição federal, ainda que seja um significativo avanço e a eleva-

\footnotetext{
${ }^{2}$ Em termos sociais, Santos (1979) observa que o governo Vargas inaugura o conceito de "cidadania" que não existia até então no Brasil. Entretanto, essa cidadania é uma "cidadania regulada", à medida que se restringe aos trabalhadores formalizados e reconhecidos pela lei. Todos aqueles indivíduos cuja ocupação a lei desconhece ficam à margem da cidadania, assim como os desempregados e subempregados.
} 
ção do patamar de civilidade construído por amplos setores da sociedade, por si só não foi, nem é, capaz de mudar a estrutura de relações sociais. A própria eleição de Luiz Inácio Lula da Silva, em 2002 - fruto de associação entre partidos de esquerda, setores populares e do empresariado - é a manifestação da demanda por uma alternativa ao projeto social-liberal, representado pelo PSDB.

Simbolicamente, o novo governo criou um conselho amplo sob o título de Conselho de Desenvolvimento Econômico e Social (CDES), com uma composição típica da colaboração de classes e de segmentos.

Paula observa, no entanto, que, apesar das expectativas e das novas possibilidades de democracia que se manifestavam no Brasil, o governo Lula teria permanecido "reproduzindo as práticas gerencialistas da gestão anterior", não investindo no controle social, como se esperava (Paula, 2005:158). Obviamente, a "gestão societal" não depende exclusivamente das ações do governo, mas este parece ter, na história brasileira, um peso significativo para que não acontecesse o pleno desenvolvimento da participação ativa dos cidadãos na construção de políticas públicas. Pode-se, com toda a razão, supor que o oposto - um determinado empenho do governo - teria efeitos positivos na ampliação da democracia para além da democracia representativa.

É importante salientar que, via de regra, a literatura pesquisada não propõe que a democracia representativa seja inteiramente substituída pela democracia direta. Hirst (1992), em A democracia representativa e seus limites, faz a crítica não à democracia representativa em si, mas àquela existente na sociedade atual, que, em nome de valores democráticos, exclui os cidadãos das decisões públicas. Conforme diz, hoje não seria viável a democracia direta nos termos classicamente definidos. Mas é necessário, afirma, criar mecanismos de representação não excludentes, que estimulem a mobilização social.

Paula (2005:159) observa igualmente que é preciso distinguir as ações políticas pertencentes à esfera de cidadania e direitos humanos e as que dizem respeito à burocracia pública. Estas, ao envolverem questões técnicas, fogem ao alcance da opinião pública, mas como o processo de políticas públicas é técnico e político, cabe assegurar condições de ambas as dimensões acontecerem.

Outros estudiosos de políticas públicas (Saravia, 2006; Kingdon, 1984; Lobato, 2006; Secchi, 2010) concordam com Paula (2005) no sentido de que o ciclo da política pública é político, com uma vertente técnica.

Tratando do contexto atual brasileiro, Lobato considera que o fim do socialismo real e o avanço do neoliberalismo reabilitaram o princípio liberal de que o Estado deve ser mínimo, deixando assim "o resto (sic) para o mercado" (Lobato, 2006:308). Contudo, se os direitos civis e políticos são compatíveis com os princípios liberais, os direitos sociais, por sua vez, "requerem um outro grau de arranjo social, que parta do coletivo e a ele se dirija" (Lobato, 2006:309). Para ela, é a cidadania - conceito estritamente ligado à democracia - o canal que faz o Estado interagir com a sociedade, viabilizando políticas e direitos sociais. Mas nos países de democracia tardia, como o Brasil, as demandas sociais incorporadas pelo Estado não 
contaram com a participação dos cidadãos. Nas palavras de Lobato (2006:309), "a universalização de bens sociais não passou pela cidadania, mas pela extensão de privilégios".

Localizando no tempo a evolução mais recente da democracia no Brasil, do ponto de vista oficial e institucional, há três momentos expressivos no contexto brasileiro em que a participação e a cidadania ganham destaque. O primeiro pode ser identificado, com clareza e fartura de referências, na Constituição de 1988, cujos traços gerais de certo modo correspondem ao conceito de cidadania de Marshall (1950), aquele em que se exigem os chamados três direitos - o civil, o político e o social. Na Constituição, como dito anteriormente, encontramse, entre outros apelos à cidadania, os chamados Conselhos setoriais.

O segundo momento expressivo foi representado pelo advento do orçamento-participativo, iniciativa que é objeto de disputa entre o PT gaúcho e o PSDB paulista, mas que por vários motivos se inscreveu na imagem e na prática mais forte e mais frequente do Partido dos Trabalhadores. A experiência das prefeituras de Porto Alegre, Mauá, Ribeirão Pires, Santo André e outras prefeituras brasileiras trouxe ao ambiente político um exemplo concreto de participação popular, ainda que com inúmeras limitações que vão do pequeno percentual do orçamento posto sob a decisão participativa até outras vicissitudes da política partidária (Carvalho e Felgueiras, 2000).

O terceiro momento diz respeito à reforma do Estado, empreendida pelo governo FHC, entre os anos 1995 e 1999, a que já se fez referência. Ali também existe a valorização do controle social, verificando-se porém uma frustrante prática de quase desconhecimento dessa dimensão da reforma e prevalecendo, como já comentado, o viés gerencial da New Public Management (NPM)

Talvez por força do caráter legal, dado que decorre de um dispositivo constitucional, podemos dizer que institucionalmente restaram os conselhos setoriais como instrumentos reais de controle social. É por isto mesmo que sobre eles queremos colocar o foco de nossas atenções.

\section{Participação nos conselhos gestores de políticas públicas}

Os conselhos como forma de organização não são recentes. Como mostram Gohn (2000) e Teixeira (2005), há exemplos de conselho na Revolução Francesa e na Comuna de Paris (1871), são conselhos os Soviets de Petrogrado (1905) e seus semelhantes na Revolução Russa (1917), houve os Conselhos dos Operários de Turim, os conselhos alemães, os conselhos iugoslavos (anos 1950), que ofereceram os melhores exemplos de moderna autogestão, dentre outras experiências semelhantes.

Sua origem possui três fontes distintas. "A primeira é resultante de movimentos insurrecionais, como meio de organização revolucionária que é, ao mesmo tempo, aparato de poder e sistema alternativo de representação" (Teixeira, 2005:99). Nesse grupo estão as experiências da Revolução Francesa, da Comuna de Paris e dos Soviets. A segunda vertente compreende os conselhos de locais de trabalho, que se organizam em "assembleias operárias e representa- 
ção por meio de delegados de seção de fábrica" (Teixeira, 2005:99). Nesta vertente estão os "conselhos operários", os "conselhos de fábrica" e os "conselhos populares", experimentados na Itália, Espanha, Iugoslávia, Polônia e Alemanha. A terceira vertente engloba os conselhos estudados neste trabalho. Segundo Teixeira, estes "surgem nos países de capitalismo avançado como arranjos neocorporativistas com objetivo de negociar demandas de trabalhadores, usuários e outros grupos de interesse e reduzir conflitos distributivos" (Teixeira, 2005:100).

O autor lembra ainda que os Conselhos emergem em circunstâncias de crise institucional e revolucionária, de insuficiência de legitimidade dos sindicatos e de crise do Estado.

No Brasil, houve experiências a partir dos anos 1960, como os conselhos comunitários e os "conselhos de notáveis" que, no período ditatorial, atuavam nas instâncias governamentais. Nos anos 1980 surgem os conselhos populares inaugurando uma nova forma de organização de movimentos sociais (Gohn, 2000:35). O que é recente em nosso país são os Conselhos Gestores de Políticas Públicas, instituídos legalmente, com caráter consultivo e/ou deliberativo, que se incluem na terceira vertente descrita por Teixeira (2005). A Constituição de 1988 é referenciada como o marco impulsionador da criação dos mesmos.

Dando consequência à Constituição Cidadã, os Conselhos Gestores de Políticas Públicas foram criados por leis específicas, como referido anteriormente, atendendo às reivindicações dos movimentos sociais. Como exemplo, é possível citar a Lei no 8.142, de 1990, que institui a Conferência e o Conselho Nacional de Saúde; a Lei no 8.742, de 1993, que cria o Conselho Nacional de Assistência Social; a Lei no 9.131, de 1995, que institui o Conselho Nacional de Educação.

\subsection{As experiências dos Conselhos Gestores: uma leitura empírica}

Aqui serão descritas e analisadas as observações empíricas realizadas nos Conselhos Municipal de Saúde de Niterói, Municipal de Assistência Social do Rio de Janeiro e Estadual de Saúde do Rio de Janeiro. Tais análises serão complementadas por bibliografia de estudos de caso em Conselhos Gestores de Políticas Públicas no Brasil.

A metodologia utilizada nesta pesquisa, além das pesquisas bibliográficas e documentais, foi a "observação estruturada" e "não participante" (Vergara, 2009), ${ }^{3}$ realizada entre junho e dezembro de 2011.

O método da observação estruturada, ainda que não participante, uma vez que para isto seria necessária a condição de conselheiro, permitiu um ponto de observação menos sujeito ao envolvimento nos temas e debates. As muitas horas passadas na observação da instalação das

\footnotetext{
${ }^{3}$ Segundo Vergara, observação estruturada é uma observação planejada, uma vez que o pesquisador a faz com critérios e objetivos previamente definidos. Observação não participante, por sua vez, é aquela em que o pesquisador permanece como espectador, não interferindo na realidade observada.
} 
reuniões, da relação entre os conselheiros e de sua atuação formal e informal enriqueceram a pesquisa e deram sentido a certas informações obtidas nas entrevistas.

Esta observação é aqui descrita, em certos momentos, pormenorizadamente, com a finalidade de oferecer ao leitor uma exposição onde se possam perceber aspectos significativos, ainda que pequenos. Estes e outros aspectos, combinados com as entrevistas, vão adquirir consistência como elementos de análise empírica.

Ao todo foram feitas oito entrevistas com conselheiros do CMAS/RJ e CES/RJ. As entrevistas tiveram, em média, duração de uma hora cada. No CMS/Niterói apenas a secretária do Conselho foi entrevistada, e essa entrevista durou 40 minutos. Na reunião do Conselho Estadual de Saúde do Rio de Janeiro foram feitas também entrevistas com seis conselheiros. O primeiro contato estabelecido foi via pesquisa pela internet. Dos três Conselhos (Municipal de Saúde do Rio de Janeiro e Municipal de Saúde de Niterói e Estadual de Saúde), apenas o estadual possui uma página eletrônica, na qual disponibiliza o regimento interno, o calendário das reuniões, os nomes dos conselheiros, dentre outras informações. Há um link para as atas, entretanto a mais recente datava de janeiro de 2011. O Conselho Municipal do Rio de Janeiro possui um link no site da Secretaria Municipal de Saúde, contudo não disponibiliza nenhuma informação a respeito do funcionamento do Conselho, de sua estrutura ou qualquer meio de contato (telefone, e-mail etc.). Já o Conselho de Niterói não possui link em qualquer página eletrônica. O contato obtido através de um telefone da Fundação de Saúde do Município de Niterói informou o número do telefone do Conselho e a data da reunião. Ao ser questionada sobre a existência de um meio de divulgação do Conselho, a funcionária da prefeitura, responsável pela secretaria do Conselho, negou a não existência de um site, mas não soube dizer o endereço eletrônico.

A tentativa de participar do Conselho Municipal de Niterói foi frustrada duas vezes. $\mathrm{Na}$ primeira, ao ligar para confirmar, a secretaria informou que não haveria a reunião. Na segunda ocasião, ao chegar no auditório onde elas ocorrem, informaram que a reunião tinha sido cancelada. As informações levantadas foram adquiridas apenas a partir de entrevista com a secretária do Conselho na Secretaria de Saúde do município, uma vez que o Conselho não disponibiliza os documentos internos (tais como atas e regimentos), nem os nomes e contatos dos conselheiros. ${ }^{4}$ Nesta mesma entrevista, a funcionária disse que não há um sistema de reposição das reuniões. Uma vez cancelada, só haverá outra no mês seguinte.

O Conselho Estadual, por seu turno, inicialmente tentou condicionar a participação dos pesquisadores, como ouvintes, na reunião do Conselho ao encaminhamento de uma permissão da autoridade municipal para realizar-se a pesquisa. Ao serem questionados sobre a publicidade das reuniões, a secretária executiva e o secretário de Saúde, presidente do Con-

\footnotetext{
${ }^{4}$ Esta mesma secretária argumentou que, para ter acesso aos documentos, que são públicos, a pesquisadora deveria encaminhar um pedido formal, emitido pela instituição da qual faz parte, porque os conselheiros querem que sejam dadas satisfações sobre o que se pesquisa nesse Conselho. O pedido foi encaminhado, mas até o momento da redação deste trabalho não houve resposta, passados seis meses.
} 
selho, corrigiram a informação afirmando que a participação é livre, mas os pesquisadores não poderiam entrevistar os Conselheiros. No entanto, no espaço da reunião, os conselheiros — representantes dos sindicatos, dos usuários e das associações — dispuseram-se não só a responder à entrevista, como manifestaram o desejo de que os pesquisadores retornassem às reuniões seguintes. Havia, por parte dos representantes dos profissionais da área, a demanda por ampliar o número de participantes, ainda que não conselheiros, para, segundo suas palavras, constranger o poder público, e os conselheiros por ele cooptados, a serem mais democráticos. Esta reunião, composta por 42 membros, entre os quais conselheiros e observadores, ${ }^{5}$ foi a terceira seguida em que não houve quorum. Ainda assim, foi marcada por protestos de representantes dos usuários e dos sindicatos dos médicos, dos psicólogos e dos enfermeiros. Reclamavam da falta de transparência nas decisões, da omissão do Conselho em discutir os problemas dos hospitais e da "privatização da saúde pública", nas palavras do representante sindical dos médicos. Reclamavam também por terem seus pleitos ignorados naquele espaço. Sustentavam que há um processo de "cooptação clientelista" de vários conselheiros, por parte do secretário de Saúde. Nas palavras do representante dos médicos:

Este Conselho nunca se dignou a sequer pautar este tema [da privatização da saúde pública]. O que vem acontecendo é crime. O Conselho não pode se omitir disso. Exijo que hoje seja marcada a data para este Conselho debater a crise da saúde pública. Já fiz esta solicitação não sei quantas vezes. Estou há dois anos neste Conselho pleiteando que aconteça uma reunião para discutir a Rede Própria. Temos que fazer uma reflexão sobre o funcionamento e estrutura de saúde. Não se discute atendimento de saúde aqui. Não se discute atividades-fim do SUS. ${ }^{6}$

\footnotetext{
${ }^{5}$ Pelo regimento (Disponível em: <www.conselhodesaude.rj.gov.br/regimento-interno.html>. Acesso em: 28 jan. 2012.), o CES possui 28 conselheiros, distribuídos paritariamente entre representantes dos prestadores de serviços públicos e privados (25\%), representantes dos trabalhadores da área da saúde (25\%) e representantes dos usuários (50\%). Os prestadores de serviços são distribuídos em: a) secretário de Estado de Saúde (membro nato e presidente do Colegiado); b) 1 representante das Universidades Públicas; c) 1 representante do Conselho de Secretários Municipais; d) 1 representante da Secretaria de Estado de Segurança Pública Corpo de Bombeiros Militar do Estado do Rio de Janeiro; e) 1 representante do Conselho Estadual dos Direitos da Mulher; f) 1 representante dos Hospitais Privados, conveniados com o Sistema Único de Saúde (SUS); g) 1 representante dos Hospitais exclusivamente Filantrópicos, conveniados com o SUS.

Representantes dos profissionais da área de Saúde: a) 4 representantes dos Sindicatos da área de saúde; b) 3 representantes dos Conselhos de Profissionais da área de saúde.

Representantes dos usuários: a) 2 representantes de entidades de moradores, de âmbito estadual; b) 2 moradores em favelas, de âmbito estadual; c) 1 representante de movimentos não governamentais de Defesa do interesse da Mulher, de âmbito estadual; d) 3 representantes dos usuários nos Conselhos Municipais de Saúde; e) 1 representante de trabalhadores na área rural, no âmbito estadual; f) 2 representantes de centrais sindicais, não pertencentes à área de Saúde; g) 1 representante de entidade de defesa dos interesses dos aposentados, de âmbito estadual; h) 2 representantes de entidades de portadores de deficiências.

${ }^{6}$ Esta declaração foi dada no dia 3 de junho de 2011. Nas duas plenárias subsequentes tal questão não foi discutida nem agendada para reuniões posteriores.
} 
Outros conselheiros demonstraram relativa alienação daquele processo. Afirmaram desconhecer o regimento interno e a pauta daquela reunião, ficaram apáticos em face dos protestos dos colegas e diziam estar contentes com suas atuações e com o Conselho em si. Alguns deles não se tornaram representantes por meio de eleição. Tornaram-se conselheiros a partir de convites feitos pela presidência do Conselho. O representante da Federação das Associações de Moradores de Favelas do Estado do Rio de Janeiro (Faferj), que ocupa a vaga de usuários, afirma ter cadeira cativa no Conselho. Demonstra indignação com o fato de que há algum tempo estão, nas Conferências de Saúde - espaço onde ocorrem as eleições para conselheiros - , tentando acabar com essas "cadeiras cativas". Este mesmo conselheiro também afirma desconhecer a pauta da reunião que teria sido realizada naquele dia, bem como desconhecia o regimento interno. Quando perguntado se tem obtido bons resultados para o grupo que representa (Faferj), a resposta deste conselheiro foi "não sei".

O representante dos usuários com doenças patológicas denunciou que "a forma de eleição na Conferência é maracutaia" e acrescentou que "isso é uma máfia. Vários conselheiros surgem pelas mãos do secretário, que lhes dá posto em troca de favores".

Em todas as reuniões acompanhadas, a postura do secretário estadual de Saúde, presidente do Conselho, foi centralizadora. Na reunião ocorrida no dia 3 de junho de 2011, ele suspendeu a plenária por falta de quorum. Aproximadamente 15 minutos após a suspensão, chegou o conselheiro que completaria o quorum, mas o secretário não voltou atrás em sua decisão. Houve protestos por parte de alguns conselheiros, o que acabou em exaltação das duas partes. Alguns conselheiros pediram "questão de ordem". O presidente repeliu os pedidos, repetindo que "não tem questão de ordem, conselheiro! Não tem questão de ordem" e encerrou a plenária. Em argumento conclusivo afirmou que "não tem questão de ordem se não tem plenária".

Nas experiências destes dois conselhos chamou a atenção o fato de que, pelo caráter deliberativo dos mesmos, as reuniões ordinárias, como espaços legítimos e instituídos por lei para que se tomem as decisões do setor, ao não ocorrerem, prejudicam o próprio andamento das questões na área de saúde. Nesse sentido, pode-se concluir que, se as decisões não são tomadas nesses espaços, elas necessariamente serão tomadas, por outros mecanismos, em espaços paralelos.

Um dado interessante que apareceu tanto no Conselho Municipal de Niterói quanto no Conselho Estadual do Rio de Janeiro foi que não há representantes dos planos de saúde privados na composição do Conselho. Nos dois casos, a não participação partiu da iniciativa dos próprios prestadores de serviço nas Conferências (instância que elege os conselheiros). Isso corrobora a informação dada por Labra de que "os prestadores privados praticamente não participam porque resolvem seus pleitos diretamente com o gestor ou seus funcionários e, quando presentes, coíbem a livre expressão dos demais conselheiros, em particular os do segmento dos usuários" (Labra, 2006:15).

O Conselho Municipal de Assistência Social-RJ possui uma dinâmica um tanto diferente. As plenárias ocorrem em um auditório no prédio da Prefeitura. Nas três reuniões observadas, este auditório estava repleto de pessoas. Significa que há muitos não conselheiros que 
comparecem às reuniões periodicamente. Nos dias de plenárias, diferentemente do que ocorre nos Conselhos de Saúde, o auditório fica aberto. Qualquer pessoa pode entrar sem ter que se identificar. A ata das reuniões é disponibilizada a todos no início da sessão. O regimento do CMAS-RJ não estabelece quorum. Portanto, independentemente do número de conselheiros presentes, a plenária acontece. Neste Conselho há um sistema de rodízio entre poder público e sociedade civil para a mesa diretora, inclusive para o cargo de presidente.

Segundo a conselheira representante da sociedade civil que foi presidente do CMASRJ e do Conselho Municipal da Criança e do Adolescente do Rio de Janeiro, há grande dificuldade em dar andamento às atividades do Conselho - aquelas que não se restringem às plenárias mensais, mas a uma rotina ao longo do mês — porque o número de conselheiros é pequeno (20) e grande parte é ausente. Essa conselheira reclama também da falta de apoio técnico. Em suas palavras:

comparando, por exemplo, o Conselho Municipal de Direitos da Criança e do Adolescente de São Paulo (CMDCA-SP) e o do Rio de Janeiro: aqui a gente só tem uma salinha precária. É precária mesmo, muito ruim. Se você observar, as piores salas da prefeitura são as salas dos Conselhos, sempre. É aquela que o carpete está soltando, que tem infestação de barata. A gente tira os processos e as baratas saem... E a infraestrutura é praticamente nenhuma. Em São Paulo, o CMDCA ocupa dois andares de um prédio da Prefeitura, tem nove funcionários da prefeitura disponíveis, dois carros à disposição para os conselheiros fazerem as visitas. Aqui no Rio, para fazer as visitas, temos que ir em uma Kombi velha, sacudindo e que temos que pedir com muita antecedência, correndo o risco dela não aparecer no dia agendado. Então, os Conselhos do Rio são muito precarizados, embora eles sejam considerados os mais combativos do país. Acho que por isso mesmo são sucateados.

Chama a atenção, nesta fala, que a vinculação do Conselho com a Prefeitura não é questionada. O Conselho depende do apoio da Prefeitura para funcionar em todas as esferas. A autonomia do Conselho, neste aspecto, apesar de não se definir como problema, é algo a ser destacado.

Contando como se tornou conselheira, ela relata que frequentava periodicamente o CMAS-RJ como representante de uma instituição beneficente fundada por ela. Até que uma amiga, na época já conselheira, convidou-a para se candidatar ao cargo. Na primeira tentativa, conseguiu se eleger e logo depois se tornou presidente do mesmo. Para se tornar elegível ao cargo de conselheiro, basta que representantes de entidades beneficentes ou ONGs cadastrem suas organizações na prefeitura. Foi o que ela fez.

Observa-se, neste caso, que a despeito de se tratar de um Conselho com maior presença da sociedade, os cargos de conselheiros não são gerados a partir da mobilização de movimentos sociais. A conselheira representa — ou seja, deve satisfações — a instituição cuja porta-voz e proprietária é ela própria.

Em consulta ao Regimento Interno do Conselho Estadual de Assistência Social do Rio de Janeiro (Ceas/RJ), bem como à Resolução Ceas/RJ nº 005/10, de 29 de junho de 2010, 
que estabelece o edital de convocação do processo eleitoral de representantes da sociedade civil para a gestão 2010-12, a lógica de representação é a mesma do CMAS/RJ. O art. $4^{\circ}$ deste último documento estabelece que "Poderão habilitar-se ao processo eleitoral na condição de eleitores e/ou candidatos, os representantes ou organização de usuários, as entidades e organizações de assistência social e dos trabalhadores do setor" (Conselho Estadual de Assistência Social, 2010). Para o processo eleitoral, é formado um colégio eleitoral e todos os candidatos são escolhidos nesse pleito geral. Em outras palavras, os representantes da sociedade civil não são escolhidos por sua base de origem, mas pelo conjunto de pessoas aptas a votar, que se inscrevem de acordo com as normas estabelecidas pelo regimento interno e pelo edital supracitado.

\subsection{O concreto pensado: análises sobre os Conselhos Gestores}

Nossa observação direta sobre os conselhos gestores foi um contato delimitado com o concreto. Proporcionou uma forte impressão sobre variados aspectos do funcionamento daqueles conselhos - materializando e personificando problemas que se haviam colocado, até então, apenas em plano teórico. Esse concreto observado, os Conselhos Gestores, desde a sua criação, tem sido objeto de estudos, cuja cobertura nacional é razoavelmente expressiva.

Esta Revista de Administração Pública, em números passados, já ofereceu aos seus leitores artigos analisando a participação da sociedade civil na gestão pública. Mais diretamente relacionados, cabe citar o trabalho de Milani (2008), reunindo avaliações realizadas por analistas da Europa e da América Latina acerca do orçamento-participativo e do planejamento urbano, e o texto de Saliba e colaboradores (2009), tratando de Conselhos de Saúde do noroeste de São Paulo, à luz de documentos oficiais e entrevistas com autoridades públicas, para orientar um programa de capacitação de conselheiros, em 2007.

Aqui estamos trazendo a observação direta e recente, realizada entre junho e dezembro de 2011, que julgamos oportuno cotejar com outras contribuições que seguiram semelhante via empírica de investigação.

De modo sistematizado, agora sob a memória e o registro do que pudemos ver, refazemos a leitura de alguns autores que se dedicaram a estudar o que têm sido os conselhos na prática.

Reunimos aqui, ainda que de forma sintética, os estudos de Abers, Serafim e Tatagiba, sobre a participação da sociedade sob o governo Lula; Bulla e Leal, acerca dos Conselhos Municipais de Assistência Social; Castro, Ferreira, Júnior e Cardoso sobre o Conselho Nacional das Cidades de onde provêm diretrizes que tocam os conselhos gestores municipais; Labra e Côrtes, em relação aos conselhos e as conferências de saúde; além de outros pesquisadores que a partir de observações diretas de situações de controle social nos trazem análises pertinentes sobre os espaços de decisão de políticas públicas, como é o caso de Lobato, Neves e Teixeira.

Comecemos com Labra, em seu trabalho intitulado "Conselhos de Saúde: visões 'macro'

e 'micro"' (2006), que nos traz algumas questões importantes, de certo modo confirmando 
nossas pessoais observações: (1) de modo geral, os Conselhos não utilizam meios de divulgação de suas atividades (revistas, páginas eletrônicas etc.), o que faz a população, via de regra, desconhecê-los; (2) a adesão pela comunidade é baixa, devido ao desconhecimento da estrutura dos Conselhos, de seus objetivos e de sua utilidade. Isso se reflete no baixo envolvimento nas eleições para conselheiros representantes dos usuários; (3) por outro lado, os Conselhos são muito valorizados por quem os frequenta. São vistos, porém, como espaços de reivindicações específicas e denúncias pontuais. "A maior parte do tempo de cada reunião mensal é gasta na discussão de assuntos internos, sendo raros os debates de temas substantivos" (Labra, 2006:13); (4) há muitas reclamações quanto à postura do secretário de Saúde, caracterizada como autoritária, desrespeitosa e irresponsável. Nas palavras da autora:

Reclama-se que não discutem o orçamento nem prestam contas da sua execução; não acatam as resoluções do colegiado; definem de antemão ou manipulam a pauta de discussão e as deliberações; impõem decisões mediante um discurso tecnocrático; esquivam discussões de teor político; cooptam conselheiros ou lideranças comunitárias com artifícios clientelistas. (Labra, 2006:13)

Além disto, Labra identifica problemas quanto à composição, à representação e à representatividade. Os critérios de escolha dos conselheiros não são bem conhecidos, o princípio da paridade nem sempre é respeitado, por vezes um mesmo conselheiro representa segmentos opostos (exemplos: um prestador de serviço e um membro do governo representando os usuários).

As avaliações sobre esses fóruns apontam para uma série de obstáculos vivenciados em seu cotidiano, o que os impede de atingir os objetivos definidos pela legislação que fundamentou sua implementação. Em outras palavras, se do ponto de vista mais geral a institucionalização da representação de interesses na construção de políticas públicas significa um grande avanço na construção de uma sociedade democrática, por outro lado observa-se considerável distância entre o que dispõe a norma jurídica e o que acontece na realidade concreta.

A autora ainda observa que o surgimento dos Conselhos Gestores de Políticas Públicas deve-se a amplas mobilizações populares que foram incorporadas na Constituinte e se tornaram referência no continente latino-americano (Labra, 2006:199). No entanto, a população brasileira aparece em pesquisas de opinião como entre as que possuem os mais baixos valores democráticos na América Latina. É o que revelam, segundo a autora, pesquisas da Pnud de 2004, o Latinobarómetro de 2002 e Abramo, em levantamento publicado em 2000. A pouca disposição dos brasileiros em exercer cidadania é um dado presente no senso comum dos próprios brasileiros e do povo latino-americano. Isso, provavelmente, tem um significado nesses espaços de gestão democrática.

Ao analisar as novas formas de participação da sociedade civil, instituídas a partir do governo Lula,7 Teixeira, Souza e Lima (2011:4) mostram que, a despeito de terem aparecido

\footnotetext{
${ }^{7}$ Os autores afirmam que "foram separadas as funções de: coordenação política do governo — competência da Secretaria de Relações Institucionais cujas ações voltaram-se às interações com o Congresso Nacional e com os entes federados; coordenação e integração das ações do governo — competência da Casa Civil; e relacionamento e
} 
"novos elementos da arquitetura da participação", na prática, novos atores sociais não foram reconhecidos como participantes legítimos. Em suas palavras:

pode ser percebido o limite do reconhecimento de novos sujeitos políticos, pois houve uma centralidade da relação capital-trabalho quando, na escolha dos representantes sociais no órgão colegiado, foram privilegiados empresários e sindicalistas. (Teixeira, Souza e Lima, 2011:6)

Os autores observam ainda, tratando dos conselhos gestores de políticas públicas em geral, que, mesmo com esses espaços abertos ao público, cidadãos que não são conselheiros dificilmente têm direito à voz. Até os suplentes são impedidos de participar livremente das reuniões. Por outro lado, esses chamam a atenção para o recorrente problema da informação. Na maioria dos casos, os atos das plenárias são publicados apenas no Diário Oficial.

As Conferências Nacionais são instâncias superiores aos Conselhos, que ocorrem a cada dois anos e têm como objetivo definir rumos, bem como escolher os representantes que serão conselheiros no mandato seguinte. Os autores observam que a escolha daqueles que têm voz e voto nessas conferências não ocorre apenas por meio de eleição. Além dos representantes eleitos, há os "natos" e os "indicados". Segundo eles, "apenas sete das 52 conferências analisadas não contaram com a representação nata, ou seja, $87 \%$ dos processos permitiram esse tipo de participação" (Teixeira, Souza e Lima, 2011:19). Adiante, os autores dizem que "em 42\% das conferências foi constatada uma modalidade de participação por indicação" (Teixeira, Souza e Lima, 2011:19).

Nesses casos, organizações de abrangência nacional participam com direito a voz e voto sem necessariamente ter vinculação com a base que dizem representar. Essa distorção, por sua vez, só ocorre porque encontra legitimação por parte do governo e das organizações que coordenam e compõem esses espaços.

Castro e colaboradores (2011), ao analisarem o Conselho Nacional das Cidades (ConCidades), destacam que este desempenhou um papel de considerável relevância, desde sua criação em 2003, à medida que viabilizou o diálogo contínuo entre os representantes da sociedade civil e os governos. Ademais, o Conselho participou ativamente da formulação de diversas políticas nacionais urbanas. Entretanto, os autores observam que o ConCidades "foi excluído da definição dos critérios e escolhas dos projetos aprovados, da discussão do orçamento do Ministério das Cidades e mesmo do monitoramento e controle social sobre as ações e programas em curso" (Castro et al., 2011:24). Como exemplo, os principais programas urbanos do governo federal, PAC e Minha Casa Minha Vida, foram formulados externamente

articulação com as entidades da sociedade civil — função da Secretaria-Geral, cujas atribuições previam criação e implementação de instrumentos de consulta e participação popular" (Teixeira, Souza e Lima, 2011:5). No âmbito da Secretaria-Geral, foi criada a Secretaria Nacional de Articulação Social, a qual coube "I - coordenar e articular as relações políticas do Governo com os diferentes segmentos da sociedade civil; e II — propor a criação, promover e acompanhar a implementação de instrumentos de consulta e participação popular de interesse do Poder Executivo" (Decreto $\left.n^{\circ} 5.364 / 2005\right)$. 
ao ConCidades. Isto, segundo os autores, deve-se ao fato de que "prevalece uma cultura urbanística tecnocrática ou disputa em torno de interesses específicos e fragmentados que, de fato, impede inovações na perspectiva da incorporação do planejamento politizado e dos pactos socioterritoriais" (Castro et al., 2011:13).

Abers, Serafim e Tatagiba (2011) mostram que a partir do governo Lula houve significativas mudanças no que concerne à forma de concepção desses espaços de decisão, tanto por parte do poder público quanto por parte da sociedade civil. Os resultados da Constituição de 1988 devem-se, em grande parte, à ampla mobilização dos movimentos sociais e sindicatos, entre outros. Nisto se incluem os fóruns de gestão de políticas públicas mais democráticos e descentralizados. Nos anos 1990, quando os Conselhos e Conferências começaram a ser construídos nos três níveis federativos, desenvolvia-se no Brasil - contraditoriamente - o projeto neoliberal. ${ }^{8}$ Por isto mesmo, a despeito de a formação de tais instâncias representar conquistas, realizações de demandas e reivindicações históricas, elas foram vistas com desconfiança pela sociedade civil organizada. Como consequência, ainda que adquirindo novos espaços institucionais, a sociedade civil continuou atuando também por fora desses espaços, por meio do trabalho de base, cotidiano, das mobilizações populares e protestos, entre outras formas de expressão.

A partir de 2003, novos espaços institucionais para gestão de políticas públicas foram criados. Houve esforços, ao menos formalmente, para ampliar os fóruns de participação e controle social. No entanto, como vimos anteriormente, a operacionalização desses conselhos, na prática, manteve diversas limitações.

No caso, por exemplo, do Ministério das Cidades, os autores afirmam que, "quando um novo ministro adepto a práticas [personalistas] entrou em cena, os movimentos sociais se adaptaram à nova situação, buscando combinar a prática institucionalizada em conselhos e conferências com negociações pessoais com autoridades públicas" (Abers, Serafim e Tatagiba, 2011:26).

Observa-se um comportamento, por parte do governo, de cooptação dos movimentos sociais e suas representações. Muitos deles trazendo um histórico de relações, quando não militância, com o Partido dos Trabalhadores e outras representações políticas que compartilham o poder.

É difícil, em face disto, não relembrar o jogo de palavras feito por Andrade e outros, em Cidadania ou "estadania" na gestão pública brasileira (2012), quando acusam a predominância do Estado nos ambientes do controle social, como tivemos também ocasião de presenciar.

Constata-se que, ironicamente, as mudanças realizadas no período Lula, que caminharam no sentido de institucionalizar novas formas de participação cidadã, em vez de promo-

\footnotetext{
${ }^{8}$ Esta contradição comprometedora da participação popular é percebida por Tenório e Monje-Reyes (2010:67) quando observam que "en Brasil y Chile, desde la década del 90, el rediseño de políticas públicas ancladas en el neoliberalismo (...) inpone fuertes condicionantes para el establecimiento de estrategias de desarollo local. Es en este marco que propuestas de descentralización y participación de la comunidad han sido efectuadas [...] en paralelo a las cada vez mayores restricciones en los gastos públicos, características de programas de ajuste fiscal".
} 
verem maior mobilização social, acomodaram os atores da sociedade civil à participação no interior do Estado, por meio da construção de relações de confiança e de negociação discreta entre esses atores e os governantes (Abers, Serafim, Tatagiba, 2011).

Em estudo realizado no Conselho Municipal de Assistência Social da cidade de Santa Maria, no Rio Grande do Sul, Bulla e Leal (2004) igualmente observam que há diversas contradições entre os avanços sociais e democráticos promovidos pela Constituição de 1988 e o que se verifica na prática.

As autoras mostram que entre os principais problemas está o fato de que a forma frequente de escolha dos 28 conselheiros é a indicação - todos os representantes do poder público, os 14 membros, são indicados e, dos 14 representantes da sociedade civil, 71,4\% são igualmente indicações (Bulla e Leal, 2004:9). Portanto, os representantes da sociedade civil não são escolhidos democraticamente e, ao não serem eleitos pela base que supostamente representam, não têm necessariamente o compromisso de levar para o Conselho interesses e demandas comunitários. Ademais, entre os três segmentos que compõem a sociedade civil (usuários, prestadores de serviço e profissionais da área), as entidades prestadoras de serviço são as mais organizadas. Mais: das cinco vagas pertencentes aos usuários, três são reservadas a conselheiros de outros conselhos municipais (Conselho Municipal dos Direitos da Criança e do Adolescente, Conselho Municipal de Saúde e Conselho Municipal do Idoso). Os usuários ficam, dessa forma, restritos a duas vagas. Como se vê, o princípio da paridade é, no CMAS de Santa Maria, seriamente afetado. Por fim, as autoras dizem que os representantes da sociedade civil não têm pleno conhecimento das atribuições de um conselheiro, bem como da legislação que rege esse conselho.

Tomando como exemplo a experiência de implementação do Orçamento Participativo (OP) no município de Barra Mansa, interior do Rio de Janeiro, Neves, recuperando uma questão já destacada, chama a atenção para o fato de que há incompatibilidade entre o projeto democrático que emerge com a Constituição de 1988 e o projeto neoliberal. O dois projetos são implementados no mesmo período, anos 1990. Nesse sentido, a autora afirma que "devemos tratar com cuidado a euforia democrática em torno das experiências participativas que emergiram no contexto da década de 1990 no auge da hegemonia neoliberal" (Neves, 2007:219).

Ela observa que esses fóruns constituem uma "aposta democrática fundamental para a construção e a afirmação de direitos na contramão ao projeto neoliberal. Por outro lado, há que se ter cuidado ao analisarmos o significado da participação e do poder de decisão desses novos atores nesse processo" (Neves, 2007:219). Ou seja, não basta que os conselhos gestores e o OP existam, é necessário que haja uma base efetiva que garanta seu funcionamento. A autora adverte que, da forma como está estabelecido, há o "risco de que essa participação e esse poder de decisão possam ser despolitizados no enfrentamento da política local, com uma forte prática clientelista, e perder seu conteúdo crítico voltado para o campo dos direitos e da democracia radical" (Neves, 2007:219).

Embora as várias constatações sejam relativamente semelhantes entre estes autores, há percepções distintas sobre seu significado. Côrtes (2009) concorda com as críticas que apontam limitações e distorções, entretanto defende que a dicotomia entre a normatização 
jurídica e a experiência empírica necessariamente existirá. A autora chama atenção para o fato de que tal tipo de abordagem acaba sendo uma armadilha. Se usarmos como parâmetro a necessidade do caráter deliberativo desses fóruns e de que o jogo de forças seja igualitário, sempre chegaremos à conclusão de que essas experiências são negativas.

O que se deve fazer, na opinião de Côrtes, é analisar como ocorre o jogo de forças entre os atores, de que maneira se formam as redes políticas, qual é o significado real dos diferentes atores - deixando de lado o que chama de significado "romântico" do projeto societário. ${ }^{9}$

A posição defendida por Côrtes (2009) mostra que há, subjacente aos fatos relatados, um debate ideológico presente.

Este debate antecede os acontecimentos e prevalece nas decisões e na organização dos fóruns de decisão, expressando o jogo de forças que, antes de se realizar nos espaços institucionalizados, realiza-se na sociedade civil.

\section{Considerações finais}

A "Constituição Cidadã", que institui diversos direitos sociais e cria órgãos democráticos e descentralizados, nos quais os cidadãos disputam o exercício desses direitos, deu-se a partir, e em paralelo, de grande mobilização popular fortemente politizada e organizada. Sindicatos, movimentos sociais, partidos políticos, entre outras formas de representação, vinham de muita atividade no curso das campanhas democratizantes e deram continuidade a isto, no desdobramento da Assembleia Nacional Constituinte.

O quadro que se verifica hoje - a rigor, de há algum tempo — é bastante diferente. Já não se vive este passado dos anos 1980, das grandes passeatas, greves e comícios, do movimento sanitarista, da campanha pelas eleições diretas, da grande mobilização pela e na Constituinte.

O passado mais recente e o presente do Brasil expõem uma sociedade desmobilizada, pouco disposta à atuação coletiva, inclinada a resolver seus problemas e alcançar seus objetivos no âmbito privado e, por isso, despolitizada ou despolitizando-se. É uma situação que parece reencontrar a descrição das instituições políticas feitas por Oliveira Vianna ou a caracterização da sociedade brasileira realizada por Sérgio Buarque de Holanda, com nuances de Faoro, em seu Os donos do poder.

Estado e sociedade parecem cumprir com um programa de insulamento, de uma parte, e, de outro, quando não a apatia, a opção individualista de recorrer ao relacional que a troca de favores permite.

\footnotetext{
${ }^{9}$ Como exemplo, Côrtes cita o conceito de usuário. Segundo ela, é um conceito muito vago. Serve bem às pesquisas de opinião e satisfação na prestação de serviços, mas não para atores inseridos no jogo de forças característico desses espaços.
} 
Ademais, é necessário observar a diferença dos movimentos sociais até os anos 1980 e esses que ainda podem ser observados na atualidade. Os anos 1980 traziam lutas por direitos universais. Hoje os movimentos estão centrados em interesses de grupos e categorias sociais ou nas iniciativas pelo reconhecimento identitário. As bandeiras políticas que eram comuns aos movimentos sociais no passado, hoje são fragmentadas. Segundo Gohn (2000), a partir dos anos 1990, aquele sujeito político autônomo, independente, foi capturado pelo Estado. A sociedade civil agora está parcialmente mobilizada por políticas públicas conduzidas pelo Estado em parceria com Organizações Não Governamentais (ONGs), que desempenham o papel de mediadoras entre a sociedade civil e o Estado. Essa mudança se verifica na produção teórica sobre os movimentos sociais nos anos 1990. Como enfatiza Gohn (2000), o foco dos estudos passa a organizações do terceiro setor, suas relações com o Estado e seu papel de prestador de serviços públicos. Essas organizações em grande medida foram se distanciando de suas origens e hoje são agentes de pesquisas, projetos e atividades de cunho assistencialista e/ou cultural, perdendo de vista o caráter reivindicatório de seu surgimento.

Em face desta relação de parceria, expressão pródiga de sentidos, com o Estado, a autonomia e combatividade das ONGs reduziram-se consideravelmente. Como mostra Fernandes (1994), se nos anos 1980 as ONGs no Brasil caracterizavam-se pela oposição ao Estado, a partir dos anos 1990 o Estado brasileiro assume as ONGs como parceiras. Estas passam a depender financeiramente do Estado e a serem orientadas por editais que determinam as escolhas dos projetos inspirados por uma política pública de governo ou pela ação social de uma empresa. Significa dizer que os movimentos sociais que representariam a sociedade civil nos conselhos gestores de políticas públicas, nas audiências públicas e nas sessões de OP deixaram de ser provenientes de mobilizações sociais, estimulados por valores gerais do projeto democrático, recolhendo-se, quando muito, à condição de instrumentos políticos de grupos de interesses.

É evidente que continuam a existir exceções, quando algumas organizações da sociedade civil, mesmo em continuada relação com o Estado, mantêm posições históricas empenhadas na construção de novos padrões de sociedade e de democracia. Mas não se encontra a densidade que os anos 1980 e parte dos anos 1990 registravam.

Este fenômeno não pode ser desassociado do contexto mais amplo no qual se encontra. Os anos 1990 são marcados por reformas que promovem desregulamentação, flexibilização de leis trabalhistas e previdenciárias, diminuição da atuação do Estado na esfera social, entre outras medidas semelhantes. Os valores ideológicos que acompanhavam os movimentos sociais até os anos 1980, relacionados a direitos universais e transformação social, foram, com a emergência da nova ordem, suplantados. Mais que isto, o resgate de valores típicos do individualismo liberal parece ter sido a semente mais fecunda de todo este contexto.

A experiência dos conselhos gestores, objeto de observação e análise neste artigo, não pode escapar destas circunstâncias. Inscritos na Constituição e na contemporaneidade da sociedade brasileira como resposta a um período rico em esperanças, valores éticos e sociais e intensa mobilização, eles parecem depender desse ambiente para funcionar com plenitude, ainda que se desfaçam do que se podem considerar exageros do romantismo político. 
Nas atuais condições, seu funcionamento é essencialmente burocrático. Não apenas no sentido negativo que se dá comumente a esta palavra, mas também na acepção que Michels (1982) lhe empresta, quando analisa o distanciamento entre as elites e as bases das organizações políticas.

A observação realizada, em que se baseia este artigo, se deu no decorrer de 2011. Ela portanto atualiza as apreciações que se deram por outros autores, muitos aqui citados, todas convergindo no sentido de revelar muitas limitações e algumas distorções nessas experiências institucionais de democratização da gestão pública.

Neste sentido, o que se percebe é que os Conselhos, ao se institucionalizarem, convertem-se em aparelhos do Estado, com as mesmas vicissitudes das demais instituições do poder político.

Assim como o controle social, lato sensu, nasce, como visto na introdução deste texto, do questionamento à efetividade da democracia representativa, também os instrumentos criados para esse controle precisam da vigilância da sociedade para bem funcionar. É uma aparente ironia, mas uma verdade dialética, que estejamos dizendo que o controle social institucionalizado pelos conselhos gestores, pelos conselhos gerais, pelos OPs e por todas as possíveis formas de representação de interesses necessitam igualmente de um controle social. Referimo-nos ao mais efetivo e construtivo dos controles, aquele que se realiza pela sociedade civil organizada, independente, autônoma e mobilizada. De certo modo, estamos reafirmando o que disse Kliksberg (2007:569), ao comentar os aspectos comuns das experiências participativas exitosas na América Latina: "lo más importante es el proceso democratizador en si".

Não bastará, portanto, que os construtores da nova democracia e da nova administra-

ção pública criem os fóruns de decisão sobre políticas públicas ou sobre orçamento. É preciso que recriemos esta sociedade civil, para que ambas, democracia e administração pública, finalmente se encontrem.

\section{Referências}

ABERS, Rebeca; SERAFIM, Lizandra; TATAGIBA, Luciana. A participação na era Lula: repertórios de interação em um Estado heterogêneo. In: ENCONTRO NACIONAL DA ANPOCS, XXXV, Caxambu, 2011. Disponível em: <www.ifch.unicamp.br/nepac/sites/default/files/publicacao/2011-artigoabers_rebecca_serafim_lizandra_tatagiba_luciana.pdf>. Acesso em 14 fev. 2012.

ANDRADE, Daniela Meirelles; CASTRO, Carolina Lescura de Carvalho; PEREIRA, José Roberto. Cidadania ou "estadania" na gestão pública brasileira? Revista de Administração Pública, Rio de Janeiro, v. 46, n. 1, p. 177-190, jan./fev. 2012.

BRASIL. Constituição da República Federativa do Brasil. Rio de Janeiro: DP\&A, 2004.

BRESSER-PEREIRA, Luiz Carlos. A reforma do Estado dos anos 90: lógica e mecanismos de controle. Brasília: Mare, 1997. 
BULLA, Leonia C.; LEAL, Maria L. M. A participação da sociedade civil no Conselho Municipal de Assistência Social: o desafio de uma representação democrática. Revista Textos e Contextos, $\mathrm{n}^{\circ} 3$, ano III, dez. 2004. Disponível em: < http://revistaseletronicas.pucrs.br/ojs/index.php/fass/article/ viewFile/973/753 > . Acesso em: 27 out. 2011.

CARVALHO, Maria do Carmo; FELGUEIRAS, Débora. Orçamento participativo no ABC: Mauá, Ribeirão Pires e Santo André. Polis, n. 34, 80 p., 2000.

CASTRO, Rafaelle de; FERREIRA, Regina; JUNIOR, Orlando; CARDOSO, Adalto. Participação e controle social nas políticas urbanas: avanços e limites do Conselho Nacional das Cidades. In: ENCONTRO NACIONAL DA ANPOCS, XXXV, Caxambu, 2011. Disponível em: <www.anpocs. org/portal/index.php?option $=$ com_docman\&task $=$ doc_view\&gid $=875 \& I t e m i d=353>$. Acesso em 22 nov. 2011.

CONSELHO ESTADUAL DE SAÚDE DO RIO DE JANEIRO. Regimento Interno. Disponível em: < http:// www.conselhodesaude.rj.gov.br/regimento-interno.html>. Acesso em: 24 set. 2011.

CONSELHO ESTADUAL DE ASSISTÊNCIA SOCIAL DO RIO DE JANEIRO. Regimento Interno. Disponível em: <http://download.rj.gov.br/documentos/10112/636089/DLFE-41008.pdf/regimento_interno.pdf>. Acesso em: 12 fev. 2012.

CONSELHO ESTADUAL DE ASSISTÊNCIA SOCIAL DO RIO DE JANEIRO. Resolução CEAS/RJ $n^{\circ}$ 005/10 de 29/06/2010: estabelece o edital e convoca o processo eleitoral da representação da sociedade civil no Ceas/RJ, gestão 2010-2012. Disponível em: < http://download.rj.gov.br/documentos/10112/636089/DLFE41011.pdf/resolucao_ceas_rj00510.pdf> . Acesso em: 12 fev. 2012.

CÔRTES, Soraya. Conselhos e conferências de saúde: papel institucional e mudança nas relações entre Estado e sociedade. In: FLEURY, Sonia (Org.). Participação, democracia e saúde. Rio de Janeiro: Cebes, 2009. p. 102-127.

FERNANDES, Florestan. Capitalismo dependente e classes sociais na América Latina. Rio de Janeiro: Zahar, 1975.

FERNANDES, Florestan. Que tipo de república? São Paulo: Brasiliense, 1986.

FERNANDES, Rubem César. Privado porém público: o terceiro setor na América Latina. Rio de Janeiro: Relume-Dumará, 1994.

FLEURY, Sonia. O Conselho de Desenvolvimento Econômico e Social do Governo Lula. In: MARTINS, Paulo Emílio; PIERANTI, Octavio. Estado e gestão pública: visões do Brasil contemporâneo. Rio de Janeiro: FGV, 2006. p. 79-105.

GOHN, Maria da Glória. Teoria dos movimentos sociais: paradigmas clássicos e contemporâneos. São Paulo: Loyola, 2000.

GREGOLIN, Maria do Rosario. A análise do discurso: conceitos e aplicações. Alfa, São Paulo, v. 39, p. 13-21, 1995.

GUERRA, Vânia. A análise do discurso de linha francesa e a pesquisa nas ciências humanas. Anais do Sciencult, Paranaíba, v. 1, n. 1, 2009. Disponível em: < http://periodicos.uems.br/novo/index. php/anaispba/article/viewFile/125/63>. Acesso em: 13 abr. 2012. 
HABERMAS, Jürgen. A inclusão do outro: estudos de teoria política. São Paulo: Loyola, 2002.

HIRST, Paul Q. A democracia representativa e seus limites. Rio de Janeiro: Jorge Zahar, 1992.

KINGDON, Jonh. Agenda, alternatives and public policies. Boston: Little, Brown, 1984.

KLIKZBERG, Bernardo. ¿Cómo avanzar la participación en el continente más desigual de todos? Revista de Administração Pública, Rio de Janeiro, v. 41, n. 3, p. 537-581, maio/jun. 2007.

LABRA, Maria Eliana. Conselhos de Saúde: visões "macro" e "micro". Civitas — Revista de Ciências Sociais, v. 6, n. 1, p. 199-221, jan./jun. 2006.

LOBATO, Lenaura. Algumas considerações sobre a representação de interesses no processo de formulação de políticas públicas. In: SARAVIA, Enrique; FERRAREZI, Elisabete. Políticas públicas: coletânea. Brasília: Enap, 2006. p. 289-313.

MARSHALL, Thomas Humphrey. Citizenship and social class. Londres: Cambridge University Press, 1950.

MARX, Karl; ENGELS, Friedrich. Manifesto do Partido Comunista. In: Textos. São Paulo: Alfa-Ômega, 1982. v. III.

MICHELS, Robert. Sociologia dos partidos políticos. Brasília: UnB, 1982.

MILANI, Carlos. O princípio da participação social na gestão de políticas públicas: uma análise das experiências latino-americanas e europeias. Revista de Administração Pública, v. 42, n. 3, p. 551579, maio/jun. 2008.

MILL, John Stuart. Governo representativo. In: WEFFORT, Francisco (Org.). Os clássicos da política. 10. ed. São Paulo: Ática, 2003. v. 2.

MOTTA, Fernando Prestes; ALCADIPANI, Rafael. Jeitinho brasileiro, controle social e competição. Revista de Administração de Empresas, v. 39, n. 1, p. 6-12, 1999.

NEVES, Angela Vieira. Espaços públicos, participação e clientelismo: Um estudo de caso sobre o orçamento participativo em Barra Mansa. Revista Katalysis, v. 10, p. 215-221, 2007.

OFFE, Claus. Problemas estruturais do Estado capitalista. Rio de Janeiro: Tempo Brasileiro, 1984.

PAULA, Ana P. Administração pública brasileira entre o gerencialismo e a gestão social. Belo Horizonte: Cepead-UFMG, 2004.

PAULA, Ana P. Por uma nova gestão pública: limites e potencialidades da experiência contemporânea. Rio de Janeiro: Editora FGV, 2005.

SALIBA, Nemre A. et al. Conselhos de Saúde: conhecendo sobre as ações em saúde. Revista de Administração Pública, v. 43, n. 6, p. 1369-1378, nov./dez. 2009.

SANTOS, Wanderley G. dos. Cidadania e Justiça: a política social na ordem brasileira. Rio de Janeiro: Campus, 1979. 
SARAVIA, Enrique. Introdução à teoria da política pública. In: SARAVIA, Enrique; FERRAREZI, Elisabete. Políticas públicas: coletânea. Brasília: Enap, 2006. p. 21-42.

SCHUMPETER, Joseph A. Capitalismo, socialismo e democracia. Rio de Janeiro: Fundo de Cultura, 1961.

SECCHI, Leonardo. Políticas públicas. São Paulo: Cengage Learning, 2010.

TEIXEIRA, Ana Claudia. Os sentidos da democracia e da participação. São Paulo: Instituto Pólis, 2005.

TEIXEIRA, Ana Claudia; SOUZA, Clóvis de; LIMA, Paula Pompeu. Arquitetura da participação no Brasil: uma leitura das representações políticas em espaços participativos nacionais. In: ENCONTRO NACIONAL DA ANPOCS, XXXV, Caxambu, 2011. Disponível em: <www.anpocs.org/portal/index.php?option $=$ com_docman\&task $=$ doc_details\&gid $=868 \&$ Itemid $=353>$. Acesso em: 22 nov. 2011.

TENÓRIO, Fernando G.; MONJE-REYES, Pablo. Ciudadania, participación y desarrollo local. Santiago do Chile: Editorial Arcis, 2010.

VERGARA, Sylvia C. Métodos de coleta de dados no campo. São Paulo: Editora Atlas, 2009.

Claudio Gurgel é professor-pesquisador da Universidade Federal Fluminense (UFF). E-mail: crmgurgel@ hotmail.com.

Agatha Justen é doutoranda da Escola Brasileira de Administração Pública e de Empresas (Ebape-FGV). E-mail: agatha_justen@hotmail.com. 